(An ISO 3297: 2007 Certified Organization)

Vol. 4, Issue 3, March 2015

\title{
Cascaded H-Bridge Five Level Inverter for Harmonics Mitigation and Reactive Power Control
}

\author{
Prof. D.S.Chavan ${ }^{1}$, Mukund S.Mahagaonkar ${ }^{2}$ \\ Assistant professor, Dept. of ELE, BVCOE, Pune, Maharashtra, India ${ }^{1}$ \\ PG Student [Power system], Dept. of ELE, BVCOE, Pune, Maharashtra, India, India ${ }^{2}$
}

\begin{abstract}
Distribution Static Compensator (DSTATCOM) which based on multi-Level Cascaded H - bridge (CHB) Inverter for mitigation of harmonics and compensation of reactive power in Power System. This CHB based inverter provides low harmonic distortion, reduced number of switches and suppression of switching losses. It also helps to improve the power factor and eliminate the Total Harmonics Distortion (THD). Proportional and Integral (PI) control is used for capacitor dc voltage regulation. A level shifted PWM (LSPWM) technique is used to analyse the performance of CHB Inverter. A CHB Inverter is considered for shunt compensation of $11 \mathrm{kV}$ distribution system. The results are obtained through MATLAB \& Simulink software.
\end{abstract}

KEYWORDS: DSTATCOM, Cascaded H-bridge Inverter (CHB), Total harmonic distortion (THD)

\section{I.INTRODUCTION}

Now days, consumers not only demands for continuity of supply but also quality of supply. WES is connected to existing grid affects the power quality due to variable nature of wind. Power quality directly deals with the quality of voltage supply. There are various parameters that affects the power quality such as voltage sag, swell, harmonics flicker etc. Power quality can be improved by reducing harmonics and controlling reactive power flow hence using STATCOM that is nothing but static compensator connected to PCC between grid and WES. A DSTATCOM is basically a converter based distribution flexible AC transmission controller, sharing many similar concepts with that of a Static Compensator (STATCOM) used at the transmission level. At the transmission level, STATCOM handles only fundamental reactive power and provides voltage support, while a DSTATCOM is employed at the distribution level or at the load end for dynamic compensation. Since a DSTATCOM is such a multifunctional device, the main objective of any control algorithm should be to make it flexible and easy to implement, in addition to exploiting its multi functionality to the maximum. Prior to the type of control algorithm incorporated, the choice of converter configuration is an important criterion. The two converter configurations are voltage source converter or current source converter, in addition to passive storage elements, either a capacitor or an inductor respectively. Normally, voltage source converters are preferred due to their smaller size, less heat dissipation and less cost of the capacitor, as compared to an inductor for the same rating.This paper focuses on the comparative study of the control techniques or voltage source converter based DSTATCOM, broadly classified into voltage control DSTATCOM and current control DSTATCOM. Under the former, phase shift control is compared with the latter, considering indirect decoupled current control and regulation of AC bus and DC link voltage with hysteresis current control. Renewable energy sources such as WES can be easily interfaced to a multilevel converter system for a high power application. This paper reviews state of the art of multilevel power converter technology.

\section{DSTATCOM PRINCIPLE}

A DSTATCOM is a controlled reactive source which includes a Voltage Source Converter (VSC) and a DC link capacitor connected in shunt, capable of generating and /or absorbing reactive power. It is analogous to an ideal synchronous machine, which generates a balanced set of three sinusoidal voltages at fundamental frequency with 


\title{
International Journal of Advanced Research in Electrical, Electronics and Instrumentation Engineering
}

\author{
(An ISO 3297: 2007 Certified Organization)
}

\section{Vol. 4, Issue 3, March 2015}

controlled amplitude and phase. angle. This ideal machine has no inertia, gives an instantaneous response, does not alter the system impedances, and can internally generate reactive (both capacitive and inductive reactive power) [4].

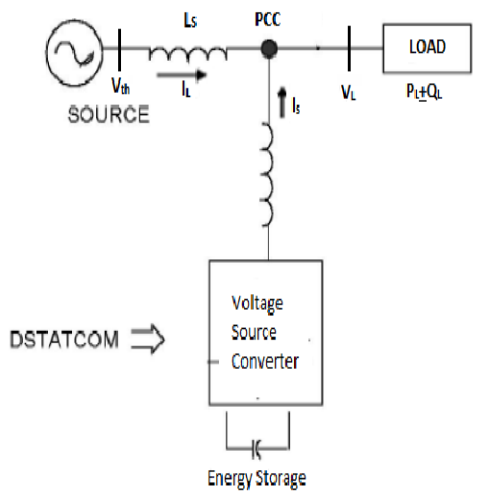

Fig.1

In Fig.1, the shunt injected current $\mathrm{I}_{\mathrm{sh}}$ corrects the voltage sag by adjusting the voltage drop across the system impedance $Z_{\mathrm{th}}$. The value of $\mathrm{I}_{\mathrm{sh}}$ can be controlled by adjusting the output voltage of the converter. The shunt injected current $\mathrm{I}_{\text {sh }}$ can be written as,

$$
\begin{aligned}
& \mathrm{I}_{\text {sh }}=\mathrm{I}_{\mathrm{L}}-\mathrm{I}_{\mathrm{S}}=\mathrm{I}_{\mathrm{L}}-\frac{\left(\mathrm{V}_{\text {th }}-\mathrm{V}_{\mathrm{L}}\right)}{\mathrm{Z}_{\text {th }}} \\
& \mathrm{I}_{\text {sh }} \angle \eta=\mathrm{I}_{\mathrm{L}} \angle \phi
\end{aligned}
$$

The complex power injection of the D-STATCOM can be expressed as,

$$
\mathrm{S}_{\mathrm{sh}}=\mathrm{V}_{\mathrm{L}} \mathrm{I}_{\mathrm{sh}}^{*}
$$

\section{REACTIVE POWER CONTROL}

A static compensator (STATCOM) is a device that can provide reactive support to a bus. It consists of voltage sourced converters connected to an energy storage device on one side and to the power system on the other. In this paper the conventional method of PI control is compared and contrasted with various feedback control strategy.

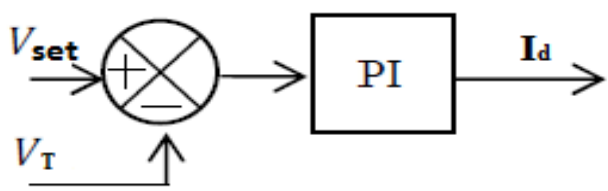

Fig 2

In this type of inverters, the fundamental component of the inverter output voltage is proportional to the DC bus voltage. So, the control objective is to regulate $\mathrm{V}_{\mathrm{dc}}$ as per requirement. Also, the phase angle should be maintained so that the $\mathrm{AC}$ generated voltage is in phase with the bus voltage. The schematic diagram of the control circuit is shown in Fig. 2. 


\section{International Journal of Advanced Research in Electrical, Electronics and Instrumentation Engineering}

(An ISO 3297: 2007 Certified Organization)

Vol. 4, Issue 3, March 2015

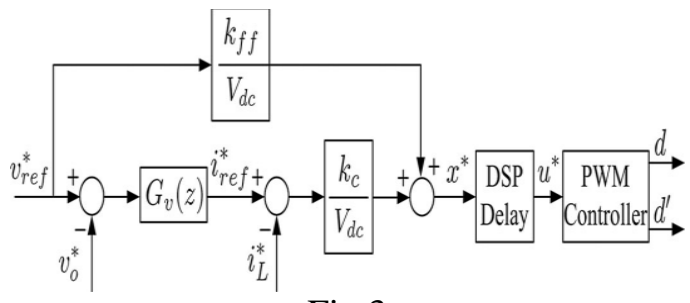

Fig.3

The controller of the stand-alone inverter is a cascaded linear controller composed of an internal current control loop and an external voltage control loop with duty-ratio feedforward $\left(\mathrm{k}_{\mathrm{ff}}=1\right)$, as is shown in Fig. 2 . The ideally sampled output voltage and inductor current are represented by $v_{0}^{*}$ and ${ }^{i_{L}^{*}}$, respectively. A proportional feedback controller is used in the internal loop with the gain of kc, while a proportional plus resonant controller is applied to the external voltage loop. The compensator of the voltage control loop is $\mathrm{G}_{\mathrm{v}}(\mathrm{z})=\mathrm{k}_{\mathrm{v}}+\mathrm{k}_{\mathrm{r}} \sum_{\mathrm{k}=1}^{\mathrm{h}} \mathrm{H}_{\mathrm{k}}(\mathrm{z})$, where $\mathrm{H}_{\mathrm{k}}(\mathrm{z})$ is the digitalized band-pass filter resonating at kth odd harmonic frequency. The ideally calculated (without delay) digital duty-ratio is $\mathrm{x}^{*}$, which is updated into the PWM controller with a DSP delay period (analog-to-digital conversion delay and computation delay).

\section{IV.CONTROL OF HARMONICS}

The speed of reference frame is varies due to harmonics present in system and for mitigation of harmonics this technique is used. In this scheme synchronous reference frame (SRF) is used which convert three component $(\mathrm{a}, \mathrm{b}, \mathrm{c})$ into two component $(\mathrm{d}, \mathrm{q})$. The voltages $\mathrm{V}(\mathrm{a}, \mathrm{b}, \mathrm{c})$ and the load currents $\mathrm{i}_{\mathrm{L}}(\mathrm{a}, \mathrm{b}, \mathrm{c})$ in terms of $\alpha-\beta$ components is calculated as per equation by (IV), where $\mathrm{K}$ is Clarke Transformation Matrix.

$$
\begin{aligned}
& {\left[\begin{array}{l}
\mathrm{I}_{\mathrm{L} a} \\
\mathrm{I}_{\mathrm{L} \beta}
\end{array}\right]=[\mathrm{K}]\left[\begin{array}{c}
\mathrm{I}_{\mathrm{La}} \\
\mathrm{I}_{\mathrm{Lb}} \\
\mathrm{I}_{\mathrm{Lc}}
\end{array}\right]} \\
& {\left[\begin{array}{l}
\mathrm{I}_{\mathrm{L} \mathrm{d}} \\
\mathrm{I}_{\llcorner\mathrm{L}}
\end{array}\right]=\left[\begin{array}{cc}
\cos \phi & \sin \phi \\
-\sin \phi & \cos \phi
\end{array}\right]\left[\begin{array}{c}
\mathrm{I}_{L a} \\
\mathrm{I}_{\mathrm{L} \beta}
\end{array}\right], \phi=\tan ^{-1} \frac{V_{\beta}}{V_{\alpha}}}
\end{aligned}
$$

where $\phi$-is the instantaneous voltage vector angle $(\mathrm{V})$ which is calculated with help of system voltages.

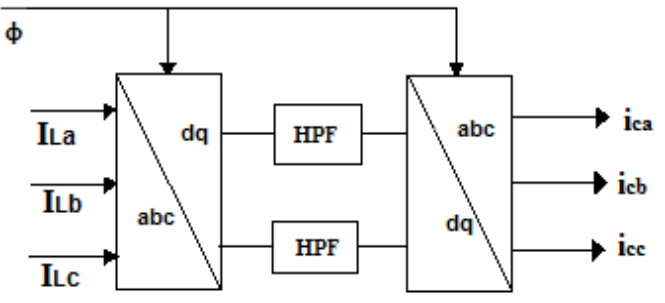

Fig.4

The SRF based conversion is shown in fig.4, where unbalanced load current $\mathrm{I}_{\mathrm{L}}(\mathrm{a}, \mathrm{b}, \mathrm{c})$ is converted into $\mathrm{I}_{\mathrm{dq}}$ component it converted back into balanced current component $\mathrm{i}_{\mathrm{c}}(\mathrm{a}, \mathrm{b}, \mathrm{c})$ shown in equation (8).

$$
\begin{aligned}
& {\left[\begin{array}{c}
\mathrm{I}_{\mathrm{Ld}} \\
\mathrm{I}_{\mathrm{Lq}}
\end{array}\right]=\frac{1}{\sqrt{V_{\alpha}^{2}+V_{\beta}^{2}}}\left[\begin{array}{cc}
V_{\alpha} & V_{\beta} \\
-V_{\beta} & V_{\alpha}
\end{array}\right]} \\
& {\left[\begin{array}{c}
\mathbf{i}_{c \alpha} \\
\mathbf{i}_{\alpha \beta}
\end{array}\right]=\frac{1}{\sqrt{V_{\alpha}^{2}+V_{\beta}^{2}}}\left[\begin{array}{cc}
V_{\alpha} & -V_{\beta} \\
V_{\beta} & V_{\alpha}
\end{array}\right]\left[\begin{array}{l}
\mathbf{i}_{\mathrm{cd}} \\
\mathbf{i}_{\mathrm{cq}}
\end{array}\right]}
\end{aligned}
$$




\section{International Journal of Advanced Research in Electrical, Electronics and Instrumentation Engineering}

(An ISO 3297: 2007 Certified Organization)

Vol. 4, Issue 3, March 2015

$$
\left[\begin{array}{l}
\text { Icomp }, a \\
\text { Icomp }, b \\
\text { Icomp }, c
\end{array}\right]=[K]^{T}\left[\begin{array}{l}
\mathbf{i}_{c \alpha} \\
\mathbf{i}_{c \beta}
\end{array}\right]
$$

Here in fig.5 Cascaded H-Bridge Inverter is shown which consists of two H-Bridge is connected together in series. This configuration provides five level voltage (named as $+2 \mathrm{~V}, \mathrm{~V}, 0 \mathrm{~V},-\mathrm{V},-2 \mathrm{~V}$ ).

\section{V.CASCADED H-BRIDGE MULTIPLE INVERTER}

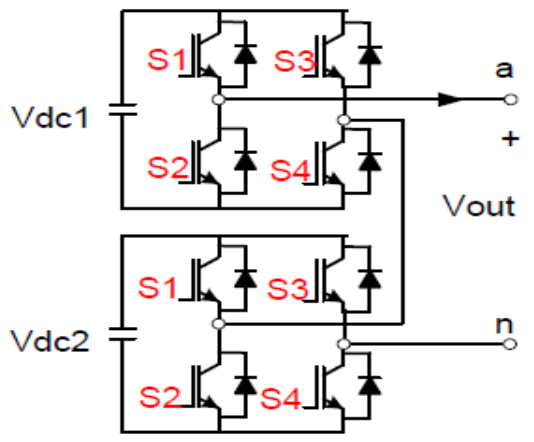

Fig.5

Operation of Cascaded H-Bridge Multilevel Inverter is based on the switching of different combination of IGBT switches. Here we get the five level of voltage shown in fig. 5 and switching scheme is given in table 1 .

Table-1:- Switching table for 5-level CHB Inverter

\begin{tabular}{|l|l|l|}
\hline $\begin{array}{l}\text { Switches Turn On } \\
\text { (Upper Bridge) }\end{array}$ & $\begin{array}{l}\text { Switches Turn On } \\
\text { (Lower Bridge) }\end{array}$ & $\begin{array}{l}\text { Voltage } \\
\text { Level }\end{array}$ \\
\hline S1, S4 & -- & Vdc \\
\hline S1,S4 & S1,S4 & $2 \mathrm{Vdc}$ \\
\hline S2, S4 & S2, S4 & 0 \\
\hline S3,S2 & -- & $-\mathrm{Vdc}$ \\
\hline S3,S2 & S3,S2 & $-2 \mathrm{Vdc}$ \\
\hline
\end{tabular}

VI.MATLAB/SIMULINK MODEL

Parameters: 1 .source voltage- $11 \mathrm{kv}$

2. AC supply frequency- $50 \mathrm{~Hz}$

3. Source resistance- $0.1 \mathrm{ohm}$ and inductance- $0.9 \mathrm{mH}$,

4.Inverter series inductance- $1642 \mathrm{e}-6 \mathrm{H}$,

5.DC bus capacitance- $10 \mathrm{e}-6 \mathrm{~F}$

6. Load resistance and inductance are chosen as $60 \mathrm{ohms}$ and $30 \mathrm{mH}$ respectively. 


\section{International Journal of Advanced Research in Electrical, Electronics and Instrumentation Engineering \\ (An ISO 3297: 2007 Certified Organization)}

\section{Vol. 4, Issue 3, March 2015}

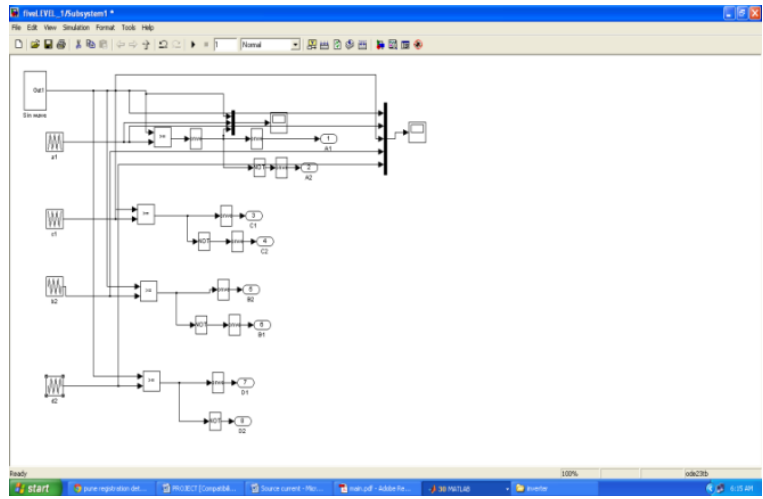

Fig. 6 STATCOM model

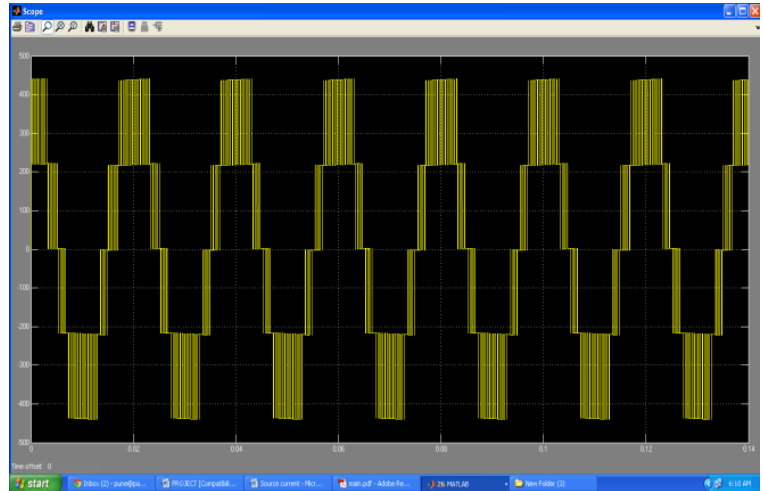

Fig. 7 - A voltage of five level output of phase shifted carrier PWM inverter

\section{VII.RESULTS AND DISCUSSION}

The results of simulation are shown bellow. The source voltage and source current, load voltage and load current are shown in waveform.

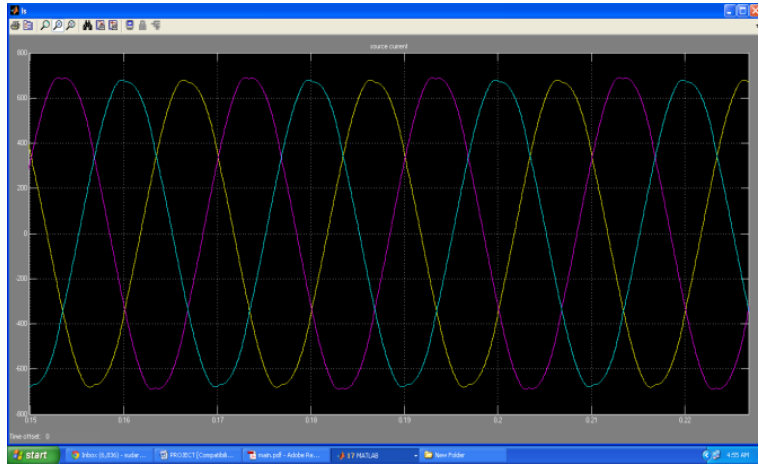

Fig.8 Source current 


\section{International Journal of Advanced Research in Electrical, Electronics and Instrumentation Engineering \\ (An ISO 3297: 2007 Certified Organization)}

\section{Vol. 4, Issue 3, March 2015}

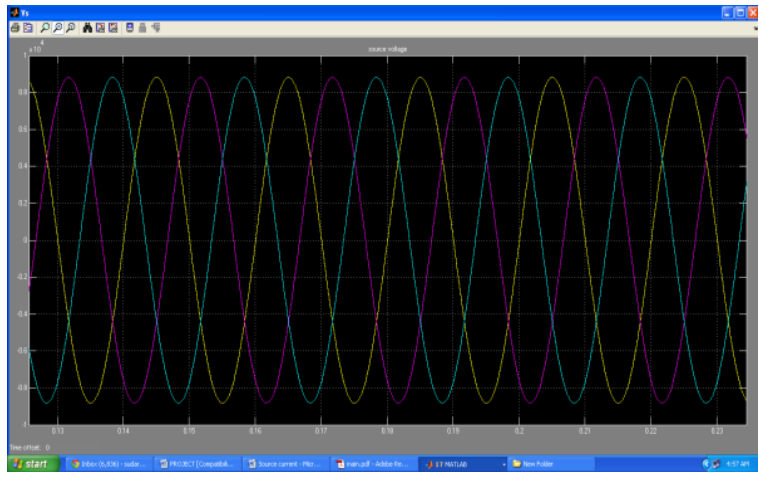

Fig.9 Source voltage

Fig.9 shows the three phase source voltage waveform. The voltage is balanced whereas fig. 8 shows waveform of three phase source current.

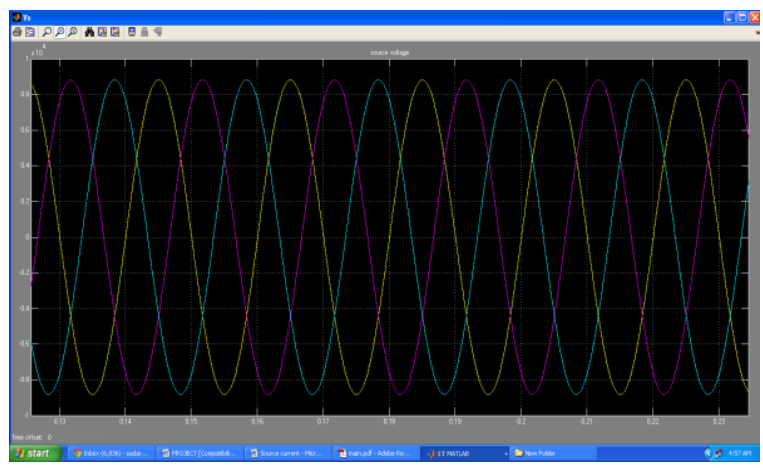

Fig.10 Load Voltage

Fig.11 shows the waveform of three phase load current. The load current contains harmonics as shown.

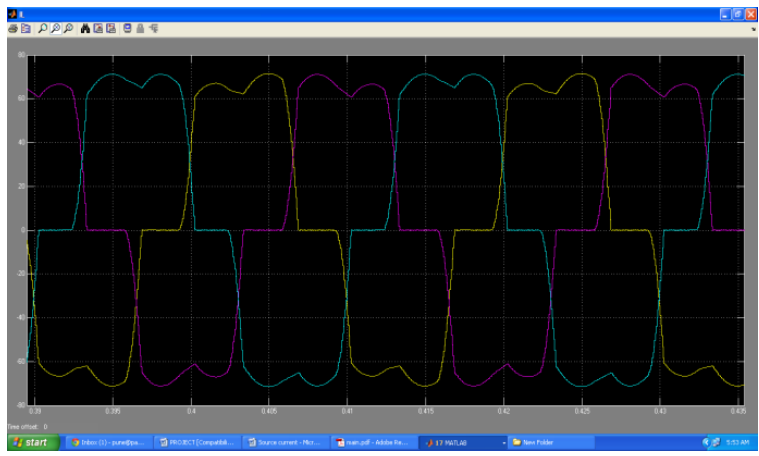

Fig 11 Load current 


\section{International Journal of Advanced Research in Electrical, Electronics and Instrumentation Engineering}

(An ISO 3297: 2007 Certified Organization)

Vol. 4, Issue 3, March 2015

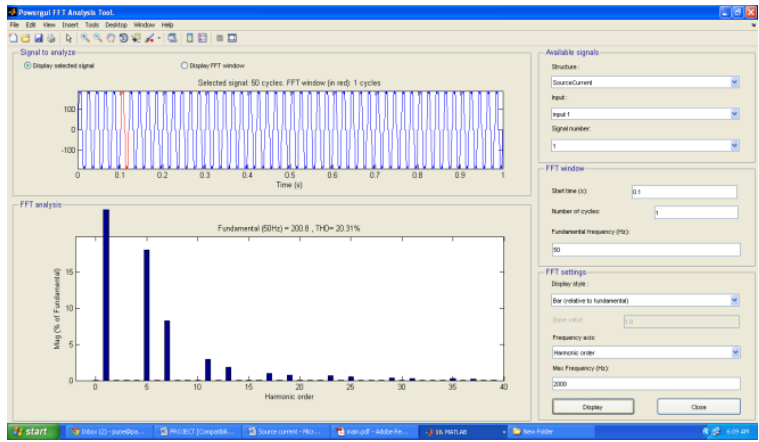

Fig.12 THD without STATCOM

In fig 12 simulation results are shown. Total harmonic distortion is calculated. THD without using STATCOM is shown in fig 12

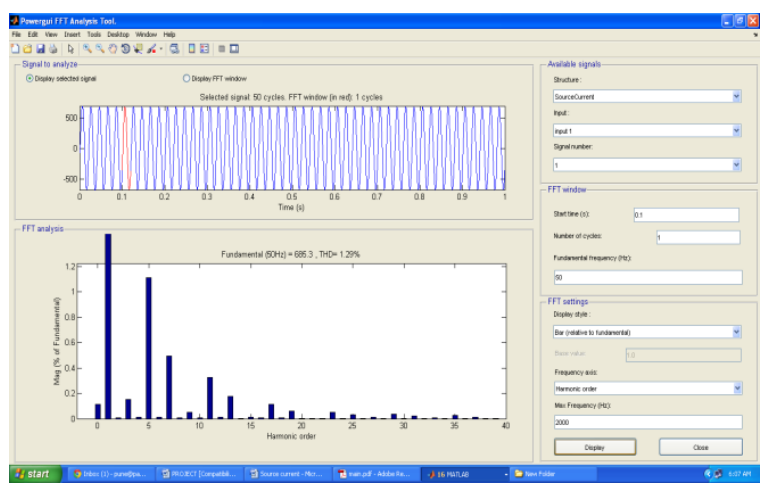

Fig.13 THD with STATCOM

In fig. 13 THD is shown when STATCOM is connected. From the data shown above THD is reduced by using STATCOM.

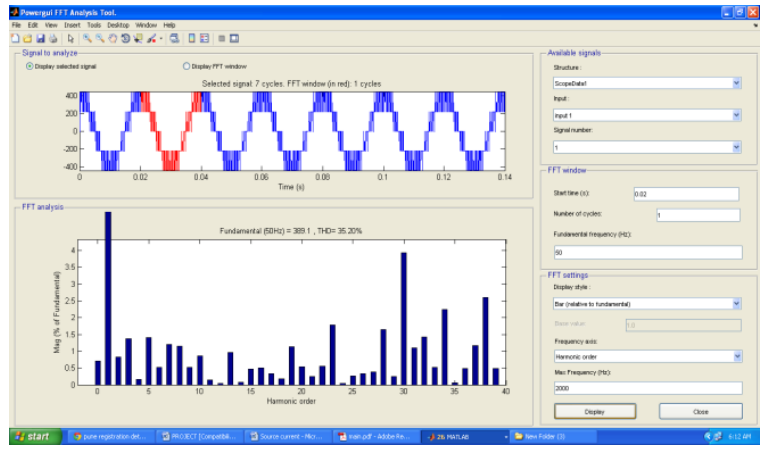

Fig.14 THD in 5-level DSTATCOM

VIII.CONCLUSION

An approach to built and evaluate its performance DSTATCOM with five level CHB inverter is presented in this paper. Multilevel CHB based converter has been completely analyzed and simulated. The source current, source voltage, load current, load voltage simulation results under nonlinear loads are presented. Using multilevel converters not only eliminate the specific harmonics but also to minimize the total harmonic distortion. By using 5-level CHB based 


\section{International Journal of Advanced Research in Electrical, Electronics and Instrumentation Engineering}

(An ISO 3297: 2007 Certified Organization)

\section{Vol. 4, Issue 3, March 2015}

DSTATCOM harmonics is suppressed to $9.73 \%$ from $20.22 \%$ THD in load current. Simulation results prove that these multilevel converters are very promising for power system applications.

\section{REFERENCES}

1. J.S.Lai. and F.Z.Peng "Multilevel converters - A new bread of converters, "IEEE Trans. Ind. Appli.,vol.32, no.3. pp.509-517. May/Jun. 1996.

2. J.Rodriguez. Jih-sheng Lai, and F Zheng peng, "Multilevel Inverters; A Survey of Topologies, Controls, and Applications," IEEE Trans. Ind. Electron., vol.49, n04., pp.724-738. Aug.2002.

3. Roozbeh Naderi, and Abdolreza rahmati, "Phase-shifted carrier PWM technique for general cascaded inverters," IEEE Trans.Power.Electron., vo1.23, no.3, pp. I 257-I 269, May.2008.

4. P.Bhagwat. and V.R.Stefanovic. "Generalized structure of a multilevel PWM Inverter:' IEEE Trans. Ind. Appln, VoI.1A-19. no.6, pp. 10571069, Nov. /Dec. 1983.

5. Gobinath.K1, Mahendran.S2, Gnanambal.I3,"New Cascaded H-Bridge Multilevel Inverter with Improved Efficiency", International Journal of Advanced Research In Electrical, Electronics And Instrumentation Engineering,’Vol.2, Issue 4, April 2013. 